psychiatric hospital because they still think of the old Victorian lunatic asylum. Many people have come to me and said, "Wouldn't he be better in a private nursing home dear?" I explain that he could not have better care than he is getting and that most nursing homes are not equipped or the staff not trained to look after someone with dementia.

Carers need help to accept the fact that when their partner no longer recognises them it is not wrong to allow the patient to be in hospital. In fact if they refuse they could end up there as well. Help is also needed so that the carer does not think they must visit every day. Visiting is distressing, but the patient does not know who the carer is anyway. I was advised always to have a friend with me when I visit, which I did once a fortnight at first. Now, on advice, I go once a month: it is like visiting a mobile corpse-Hugh is not there, only his body. The main reason for visiting is to support the staff, who understand why I do not visit often. I suspect that some of the younger staff find it hard to understand that to me my husband, who does not know me, has been dead for some years. For months now no communication has been possible when I visit.

Research is essential, and if the general practitioner thinks that the carer would be helped it is a good idea to talk about a postmortem. I saw an article in the Alzheimer's Disease Society's magazine, and it is now all arranged. For me it has helped to feel that maybe some good might come from years of sadness.

Hugh Morgan was a professor of medicine. This paper was given at the symposium for doctors on self help groups at Birmingham Medical Institute in 1989.

\title{
But what about the diet, doctor?
}

\section{Ramji Narayanan}

"Half milk and half water ... reduce chillies ... . and weak tea," said my consultant carefully. Each item was then repeated as the patient and his anxious wife nodded their comprehension.

"But," I protested later, "he's had only a hernia repair." "They like to be told," chided my consultant. "Doctor," he continued when I gave him a disbelieving look, "maybe it matters little what they eat, but if you want patients to stick to your advice in general make sure you pile on the diet recommendations whether they're correct or not."

Though he said it casually, I could not but suspect that he believed the recommendations to be correct himself. No matter; I was not willing to let that interfere with my thinking. "Eat everything, do you hear, everything that you would have if you had not been ill." My patients seemed to understand, and I was triumphant. It was obvious that a carte blanche and not a dietary restriction was just what they were hoping for.

\section{Gaining popularity}

The doubts crept in insiduously. Why was it that they smirked at me after my consultant had made his round? Could it possibly be that . . . ? I decided to have a go myself, starting with the half milk, half water homily. Surprisingly, this gained me a "gold star" every time. Without my realising it I was soon into "no chillies," "tepid drinks," and "vegetable soup without the pieces." I realised that I was fast losing my self control. Yet my relationship with my patients improved so dramatically that I soon threw my rationality to the winds and basked in my newly acquired acceptance into their circle. When I reached "two chappaties a day and increase by one every other day," I knew I was a winner.

Eight years later I pause to reflect. Am I a quack? Sifting the evidence, the answer is no. None of our patients actually starved on our diets, though, on the other hand, some of them positively bloated. A diet is obviously salutary in those (and there are a great many) who believe that the best way to convalesce is to stay in bed, expending a minimum of calories. Some of our suggestions were essentially good sense: it is prudent to warn patients who have recently had a haemorrhoidectomy against spices, and anyone can attest the agonies that follow the play of red chillies on traumatised anal skin.

Finally, think how ignorant we are of the enterocyte and its response to surgical trauma anywhere. Does it then undergo mysterious changes? Are these in the nature of a second infancy so that weaning, as it were, is in order? Perhaps a learned, fully substantiated explanation will emerge one day to caution against a rapid return to a normal diet. When that day arrives people like me will proclaim, "I knew it all along," forgetting that our patients and senior surgical colleagues had always intuitively followed these precepts.

\section{Doctor 968}

In great distress the son of a lady I have looked after for over 30 years telephoned me. His mother was a patient in an orthopaedic ward at another hospital. She had become unwell, confused, and drowsy. He and his sister could not convince the nurses that she was in danger and their efforts to see a doctor had proved unavailing. Could I help? Knowing of her obligatory sodium loss from a high output intestinal stoma, it was not difficult to guess the problem.

I telephoned the other hospital, spoke to the nurse on the ward, ascertained the name of the consultant, and asked to speak to the registrar "I'm sorry I don't know who he is." "Could I speak to the house surgeon?" "His number is 978." "Do you know his name?" "No, I'm sorry; that is his bleep number." "Could you put me back to the switchboard please?" "No, I'm sorry. ...."

I started again. "May I please speak to the doctor whose bleep number is 978?" "You need bleep control." "Bleep control?" "Yes." "May I speak to
978 please?" A pleasant male voice answered. "Are you looking after $\mathrm{Mr}$ X?" "No." "Are you Mr Y's house surgeon?" "No. His bleep number is 968."

"I began again. After a pause I spoke to a pleasant, efficient, and responsive voice. He had just received the grossly disordered results of biochemical tests he had ordered on Mrs X. It was after hours. He was glad of a chat, some information about her, and some suggestions. All went well, but it was a close shave.

Sons and daughters do know about their parents. In this instance close relatives could not break the barrier that seemed to separate them from Dr 968. My voice, known over many years, brought confidence, even though I did little. I knew how to break the communication barrier and refused to be gainsaid. Patients and patients' relatives seek from us continuity, availability, and personal contact. Are we in danger of losing something precious? - J E LENNARD-JONES, consultant gastroenterologist, London 